\title{
Bilder der Revolte
}

Eine Ausstellung des Institut français Stuttgart in Kooperation mit der Württembergischen Landesbibliothek und der BNU Strasbourg

Anlässlich des 50-jährigen Jubiläums der Aufstände des Mai 1968 zeigte das Institut français vom 16. März bis 15. Juni 2018 die Ausstellung "Images de la révolte / Bilder der Revolte". Die Schau präsentierte Plakate der 68er-Bewegung aus den Sammlungen der BNU Straßburg und der Württembergischen Landesbibliothek Stuttgart. Die Proteste, die vor 50 Jahren Deutschland und Frankreich bewegten, hatten vieles gemeinsam: die Revolte gegen die Autoritäten, die Kritik am Kapitalismus, an der Medienzensur sowie am
Vietnamkrieg und nicht zuletzt den Kampf um die sexuelle Befreiung. Den Plakaten des Jahres 1968 wurden in der Ausstellung Bilder zu aktuellen Protesten des aus Grenoble stammenden Künstlers Johann Rivat gegenübergestellt. Rivat war zuletzt Stipendiat des Austauschprogramms für bildende Künstler zwischen dem Land Baden-Württemberg und der Region Auvergne-Rhône-Alpes. Die Konfrontation der beiden Protestkulturen verweist auf Parallelen und Entwicklungen.

Christian Westerhoff

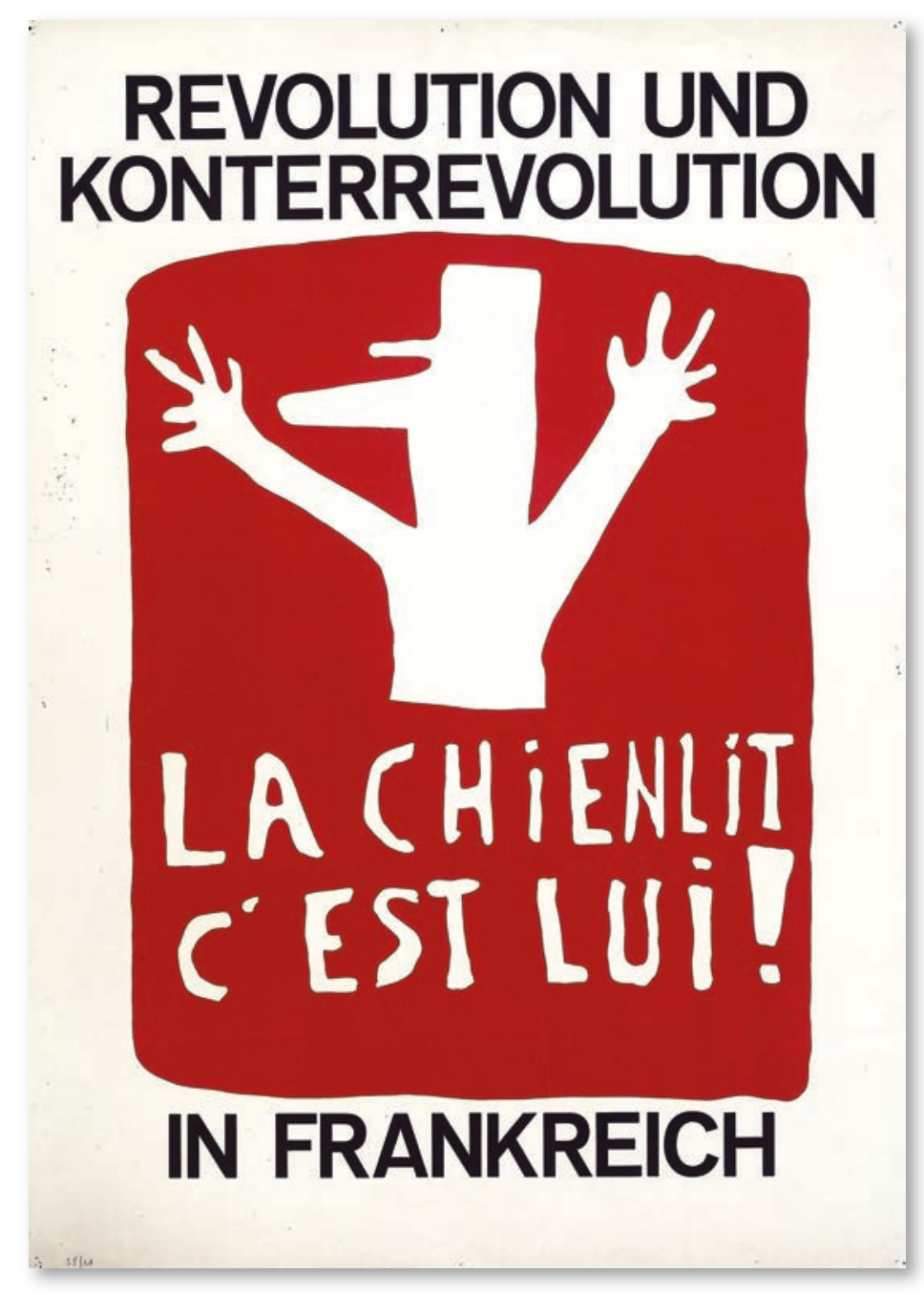

Bibliothek für Zeitgeschichte. Plakate (5.8/011) 